\title{
How did basketball teams win EuroBasket 2015? A non-standard analysis of performance based on passes, dribbling and turnovers
}

\author{
Gryko, Karol ; Mikołajec, Kazimierz ; Marszałek, Jolanta ; Adamczyk, Jakub Grzegorz ; Molik, Bartosz ;
} Waśkiewicz, Zbigniew ; Nikolaidis, Pantelis ; Knechtle, Beat

\begin{abstract}
The aim of the study was to determine the full structure of passes during EuroBasket 2015 in the context of the execution technique, creating a passing lane, the movement of the players, the ball passing direction and passing distance. In order to provide extended data, the study also analysed individual dribbling sequences, changes of dribbling direction and turnovers. The analysis encompassed 27,840 passes, 84,080 dribbles and 1467 turnovers in all matches $(\mathrm{n}=110)$ played by the eight best and the eight worst teams. Furthermore, 2030 assists were analysed to develop the model of regression. One-handed passes performed with the right hand $(\mathrm{F}=28.74$; $\mathrm{p}=0.0028$ ) were the most important predictor for the assists executed by the players of the eight best teams. Conversely, the most important predictor for the assists executed by the players from the weakest teams were two-handed overhead passes $(\mathrm{F}=21.34 ; \mathrm{p}=0.0001)$. Today, coaches must incorporate two elements of passing technique into their training regime: primarily, one-handed passes (in particular, one-handed basic passes); and secondly, two-handed passes (overhead and chest passes). Solutions should be sought with the aim of increasing the number of inside passes, which will develop the inside play.
\end{abstract}

DOI: https://doi.org/10.1080/24748668.2020.1749013

Posted at the Zurich Open Repository and Archive, University of Zurich

ZORA URL: https://doi.org/10.5167/uzh-187844

Journal Article

Accepted Version

Originally published at:

Gryko, Karol; Mikołajec, Kazimierz; Marszałek, Jolanta; Adamczyk, Jakub Grzegorz; Molik, Bartosz; Waśkiewicz, Zbigniew; Nikolaidis, Pantelis; Knechtle, Beat (2020). How did basketball teams win EuroBasket 2015? A nonstandard analysis of performance based on passes, dribbling and turnovers. International Journal of Performance Analysis in Sport, 20(3):339-356.

DOI: https://doi.org/10.1080/24748668.2020.1749013 
2 A nonstandard analysis of performance based on passes, dribbling and

turnovers

1 Department of Individual and Team Sports, Józef Piłsudski University of Physical Education, Warsaw, Poland, k.gryko@awf.edu.pl

2 Department of Basketball, Jerzy Kukuczka Academy of Physical Education, Katowice, Poland, k.mikolajec@awf.katowice.pl

3 Department of Rehabilitation, Józef Piłsudski University of Physical Education, Warsaw, Poland, marszalek.jolanta@gmail.com; bartosz.molik@awf.edu.pl

4 Department of Sports Theory, Józef Piłsudski University of Physical Education, Warsaw, Poland, jakub.adamczyk@awf.edu.pl

5 Institute of Sport Science, Jerzy Kukuczka Academy of Physical Education, Katowice, Poland, z.waskiewicz@awf.katowice.pl

6 Sechenov First Moscow State Medical University, Department of Sports Medicine and Medical Rehabilitation Moscow, Russia

$7 \quad$ Exercise Physiology Laboratory, Nikaia, Greece; pademil@hotmail.com

8 Medbase St. Gallen Am Vadianplatz, St. Gallen, Switzerland, beat.knechtle@hispeed.ch

IThese authors contributed equally to this work.

\section{Corresponding author}

Prof. Dr. med. Beat Knechtle

Medbase St. Gallen Am Vadianplatz

Vadianstrasse 26

9001 St. Gallen

Switzerland

Telephone +41(0) 712269300

Telefax +41(0) 712269301

E-mail_beat.knechtle@hispeed.ch 


\section{ABSTRACT}

42 The aim of the study was to determine the full structure of passes during EuroBasket 2015 in

43 the context of the execution technique, creating a passing lane, the movement of the players,

62

\section{3} the ball passing direction and passing distance. In order to provide extended data, the study also analyzed individual dribbling sequences, changes of dribbling direction and turnovers. The analysis encompassed 27,840 passes, 84,080 dribbles and 1467 turnovers in all matches $(n=110)$ played by the eight best teams (placed $1-8 ; n=70)$ and the eight worst teams (placed $17-24 ; n=40)$ taking part in the event. The study used a categorized observation. Furthermore, 2030 assists were analyzed to develop the model of regression. A multiple stepwise regression analysis showed that one-handed passes performed with the right hand $(\mathrm{F}=28.74$; $\mathrm{p}=0.0028$ ) were the most important predictor for the assists executed by the players of the eight best teams at EuroBasket 2015. Conversely, the most important predictor for the assists executed by the players from the weakest teams were two-handed overhead passes $(\mathrm{F}=21.34$; $\mathrm{p}=0.0001$ ). Today, coaches must incorporate two elements of passing technique into their training regime: primarily, one-handed passes (in particular, one-handed basic passes); and secondly, two-handed passes (overhead and chest passes). Solutions should be sought with the aim of increasing the number of inside passes, which will develop the inside play.

Keywords: game analysis; technique analysis; performance indicators; types of passes; dribbling; turnovers

4 5 
INTRODUCTION

67

Passes, apart from shots and dribbling, are one of the most important elements in the structure of the technical actions used during offensive play in basketball. In fact, players often perform accurate shots after passes executed with the correct technique and speed, and the points scored in this way determine the team's victory or defeat (S. Ibáñez et al., 2008). Around 60$75 \%$ of successful field goals come from passes/assists (M. Á. Gómez, Lorenzo, Sampaio, Ibáñez, \& Ortega, 2008; Miller, 1994; Oudejans, Karamat, \& Stolk, 2012).

Passing is also the fastest way to transfer the ball from the defense to offence (Tsamourtzis, Karypidis, \& Athanasiou, 2005), and is a significant element in transition offence as it allows players to quickly carry out a fast break (Cárdenas et al., 2015; Conte, Favero, Niederhausen, Capranica, \& Tessitore, 2017; Krause, Meyer, \& Meyer, 2008), as well as allowing for a quicker execution of the planned moves in half-court offence (Theoharopoulos, Lapardis, Galazoulas, \& Tsitskaris, 2010). Some coaches consider passing to be the most important technical element of offence due to its low margin of error, or even the lack thereof; if a player crosses this margin, the pass ends in an immediate turnover (Wissel, 2004; Wootten \& Gilbert, 2013). Conversely, for shots, it is assumed that a player should display an accuracy of at least 50\% (Chang, 2018; Theoharopoulos et al., 2010).

A correct dribbling technique makes changing the direction of the dribbling more effective (Andrić, 2011; Trninić, Karalejić, Jakovljević, \& Jelaska, 2010), which helps to gain an advantage in one-on-one clashes during offensive actions (Arias-Estero, 2013; Arias-Estero, Argudo, \& Alonso, 2018). It also increases the accuracy of passes, especially those performed while moving with the ball (Arias, Argudo, \& Alonso, 2012). 
Lastly, a correct technique of passes and dribbling reduces the number of turnovers (Conte, Favero, Niederhausen, Capranica, \& Tessitore, 2016). An increasing number of errors increases the odds of defeat (S. J. Ibáñez, Sampaio, Sáenz-López, Giménez, \& Janeira, 2003).

On the other hand, an improved technique of passes and dribbling reduces the number of errors, which leads to assists and the scoring of points (Angel, Tsamourtzis, \& Lorenzo, 2006;

Csataljay, O’Donoghue, Hughes, \& Dancs, 2009; S. Ibáñez et al., 2008).

Recently, we have seen an increase in the number of scientific studies on the indicators of the effectiveness of play in basketball that are based mostly on observations, which may provide us with information to use in streamlining play and training (O’Donoghue, 2009). However, the vast majority of these scientific reports concern the cooperation between players, both in offensive (i.e., tactical determinants and small-sided games) (Arias-Estero et al., 2018; Bredt et al., 2018; Conte et al., 2017; Gryko, Słupczyński, \& Kopiczko, 2016; McCormick et al., 2012) and defensive (i.e., defensive pressure on basketball shooting performance) (Csataljay, James, Hughes, \& Dancs, 2013; Sampaio et al., 2016), and to a minor degree, the technical structure of the players' actions. The most recent scientific studies analysing the shooting structure during a match take into account all the currently used types of shots (e.g. onehanded overhead shots, layups, reverse shots, hook shots and floaters), as well as the execution technique (e.g. footwork, including: while stationary, during jump shots and with catch-and-shoots after a two-count stop) (Erčulj \& Štrumbelj, 2015; Gryko, Mikołajec, Maszczyk, Cao, \& Adamczyk, 2018). However, there is a lack of such detailed studies on the structure of the other key groups of actions involved in offensive play; in particular, in relation to passes. 
The passing behaviour has only been described as assists in the traditional box score.

116 However, the numbers written down in the statistics reflect the final results of actions and

117 ignore the preceding factors. They may also omit detailed information, especially in the context of the technical execution of the players' actions or cooperation between specific formations of players. This is why the research in this area needs to continue.

The few publications concerning passes classify the passes only according to their execution technique: the highest share belonged to chest passes and overhead passes $(38.9 \%$ and $24.9 \%$, respectively) (Theoharopoulos et al., 2010). It was mentioned that the chest pass is the most basic pass, followed by the bounce pass, overhead pass, baseball pass and hand-off pass in terms of the percentages of use during a game (Theoharopoulos et al., 2010). Another study analyzed the inside pass in detail and concluded that including an inside pass during set offense and intensifying actions focused on the inside game could increase the effectiveness of the offensive actions (Courel-Ibáñez, McRobert, Toro, \& Vélez, 2016). On the other hand, the winning teams make more passes (M.A. Gómez, Tsamourtzis, \& Alberto, 2006). A publication on dribbling states that crossover dribbles and dribbles between the legs constitute the highest share of changes in the dribble direction ( $61 \%$ and $23 \%$, respectively) during EuroBasket 2009 (Andrić, 2011). passes in the context of creating a passing lane (i.e., whether the passes were executed with the creation of a new passing lane or not), the movement of the players (i.e., whether the passes were performed while stationary, while running, off the dribble or through a jump pass) or the movement of the ball (i.e., flat, lob, bounce and hand-off passes), passing 
direction (i.e., perimeter, inside and outside passes) and passing distance (i.e., short, long and skip passes). There is also a lack of information about the distribution of dribbles in individual dribbling sequences.

Analyzing the full structure of passes and dribbling and the causes of turnovers among topclass players during the most prestigious sporting events, in the context of the technical execution of these passes, has become the key factor in coaching and directly affects the effectiveness of individual players and teams. Due to the limited time in which the various techniques of passes or handling the ball can be taught during training sessions, coaches should focus on teaching the most frequently used techniques. Lastly, learning the structure of the technical actions in basketball is of fundamental importance for the practice of training, because it determines the rational choice of the training concept in order to achieve particular sports aims.

For the reasons presented above, we carried out the present study to determine the full structure of the passes occurring during EuroBasket 2015 in the context of handwork, creating a passing lane, the movement of the players and the movement of the ball, passing direction and passing distance. In order to provide extended data, the study also analyzed individual dribbling sequences, changes dribbling direction and turnovers.

\section{MATERIALS AND METHODS}

\section{Sample}

To achieve the aim of the study, 110 matches of EuroBasket 2015 were observed, for a total of 27,840 passes, 84,080 dribbles and 1467 turnovers. In the study, the structure of the passes, 
the players' movement on the court with the ball and turnovers were investigated among the best teams that ranked 1-8 in the final classification of EuroBasket 2015, as well as among those who were eliminated immediately after the group stage and were ranked 17 to 24 . The analysis encompassed 27,840 passes, 84,080 dribbles and 1467 turnovers in all matches $(n=110)$ played by the teams placed $1-8(n=70)$ and those eliminated the quickest $(n=40)$. Additionally, 2030 assists were analyzed to create the model of regression.

\section{Variables}

The categorized observation method was applied in the study, which meant that each of the games registered on DVD format was analyzed in detail in terms of the structure of the passes, dribbling and turnovers. The observations were conducted by two experts with at least 12 years of experience in coaching, including working with national teams. Recordings of all games were obtained due to access to the official FIBA server (https://gamevideos.fiba.com/login). To reliably assess the structure of the passes, dribbling and turnovers experts have used Corel VideoStudio Pro software (X5, 2012 Corel Corporation, Canada. According to the final places, the following teams were observed: Spain, Lithuania, France, Serbia, Czech Republic, Latvia - 9 games, Greece, Italy - 8 games (eight highest-ranking teams) and Russia, Germany, Northern Macedonia, Estonia, Netherland, Ukraine, Bosnia and Herzegovina, Iceland - 5 games (eliminated teams after round-robin).

Inter-rater reliability agreement, for all observations were assessed by using Cronbach's $\alpha$ statistic (Cronbach, 1951). This coefficient presents values between 0 and 1 and shows the reliability of internal consistency. A value of 1 is perfect reliability but $>0.70$ is considered 
valid (Koo, \& Li, 2016, Taber, 2018). A Cronbach's statistic of over 0.82 was obtained for all the datasets (Table 1), attesting to the reliability of the data subsequently analyzed.

First, the study investigated the structure of the passes and catches according to the following:

- passing lane:

- creating a passing lane: positioning oneself relative to the player with the ball to enable an accurate and direct pass with a minimal risk of ball loss (while evading a defending player positioned between the player with the ball and the player's partner that is to receive the ball); - without creating a passing lane;

- handwork:

- passing hand: right, left, both hands;

- technical execution of a pass: two-handed chest pass, two-handed overhead pass, one-handed basic pass, baseball pass, hook pass, behind-the-back pass, situation-related pass;

- flight path of the ball: flat, lob, bounce pass, hand-off pass;

- the player's movement during a pass: while stationary, while running, off the dribble, through a jump pass;

- passing direction: perimeter, inside, outside;

- passing distance: short (passing over to the two nearest court positions), long pass (passing the ball over a distance greater than the distance to the two nearest court positions), skip pass (a long pass to the player on the opposite side of the court); - catch after receiving the ball: one-handed, two-handed. Next, in accordance with the objectives of the study, we registered and classified the players' movements with the ball according to: 
- number of dribbles in an individual sequence: one dribble, two dribbles, three dribbles, four dribbles, five dribbles or more;

- handwork: right hand, left hand, with the change of hands;

- manner of changing direction: cross-over, under the leg, behind the back, using a reverse dribble.

Turnovers were registered according to the number of ball losses, traveling, bad passes, offensive fouls, blocks received and time violations (committed by the player and the team).

\section{Statistical analysis}

The analysis of the numerical data describing the specificity of the passes, dribbling and turnovers during EuroBasket 2015 used the following statistical measures: arithmetic mean $(\overline{\mathrm{X}})$, standard deviations (SD), percentage share in a set $(\%)$, and the confidence interval( $95 \%)$. The assumption of the normality of distribution of the studied variables was tested with the Shapiro-Wilk test and the assumption of the equality of variance was tested with Levene's test. The t-test for independent variables (two groups) was applied to determine the significance of the differences in the values describing the structure of the passes, the players' movements with the ball and the turnovers between the best teams and the teams eliminated after the end of the group stage in EuroBasket 2015. The significance of the differences of the variables, for which the assumptions of the parametric analyses were not fulfilled, was evaluated with the Mann-Whitney U-test. As the measure of the effect size, the study used the Hedges'g: small effect $<0.2$; medium effect $0.2-0.5$; large effect $>0.5$ (Ellis, 2010). In order to find a correlation between the assists and the technique of the passes executed by the players from the observed team, we applied the model of multiple forward 
stepwise regression. In all the analyses, the significance of the effects was assumed at $p<0.05$. All calculations were performed with STATISTICA software (v.12, StatSoft, USA).

\section{RESULTS}

The characteristics of the passes performed by the players from the eight best and worst teams in EuroBasket 2015, including catches after receiving the ball, are presented in Table 2.

The analysis of the values in the context of the diversification of the structure of the passes allows for the conclusion that the teams who advanced to the quarterfinals in EuroBasket 2015 executed a statistically significantly higher (by $39.7 \%, Z=4.27, p=0.001, g=0.89$ ) number of one-handed passes performed with the right hand than the teams who left the championship competition after the group stage. The opposite trend was observed for twohanded passes, in which the players from the best teams executed a significantly lower number of these (by $19.5 \%, \mathrm{Z}=-3.64, \mathrm{p}=0.001, \mathrm{~g}=0.72$ ) in comparison to the basketball players from the eight weakest teams. The highest share among all the researched teams belonged to two-handed passes (around 53-66\%) and one-handed passes performed with the right hand (around 26-38\%).

The analysis of the structure of the passes executed by both groups, in the context of the technical manner of completing a pass, revealed a significant dominance of one-handed basic passes (by $38.5 \%, \mathrm{Z}=3.29, \mathrm{p}=0.001, \mathrm{~g}=0.72$ ) and a lower number of two-handed chest passes (by $27.8 \%, Z=-4.57, p=0.001, g=1.13$ ) in the group of the best teams. In this group, onehanded basic passes constituted the greatest share, followed by two-handed chest passes (over $42 \%$ and almost $35 \%$, respectively). An opposite trend was observed in the eight weakest 
teams, where two-handed chest passes (over 48\%) constituted the greatest share, followed by one-handed basic passes (over 30\%).As far as the flight path of the ball was concerned, the players from the best teams performed lob passes more frequently (by $45.8 \%, Z=4.14$, $\mathrm{p}=0.001, \mathrm{~g}=0.54$ ), but the greatest share in both groups belonged to flat passes (around $72-$ $74 \%)$.

The analysis of the players' movements during the execution of the passes revealed that, in comparison to the teams from the second group, the eight best teams performed a higher number of running passes (by $58.2 \%, \mathrm{Z}=3.83, \mathrm{p}=0.001, \mathrm{~g}=0.52$ ) and jump passes (by $36.1 \%$, $\mathrm{Z}=2.95, \mathrm{p}=0.003, \mathrm{~g}=0.55$ ), and a lower number of passes off the dribble (by $26.1 \%, \mathrm{Z}=-2.69$, $\mathrm{p}=0.001, \mathrm{~g}=0.65$ ). However, the greatest share of all the passes (around 63-66\%) belonged to passes executed while stationary.

In terms of the direction of the passes executed by the players from the best teams, in the study a higher number of inside passes was observed (by $62.1 \%, \mathrm{Z}=5.38, \mathrm{p}=0.001, \mathrm{~g}=1.09$ ).

On the other hand, a lower number was observed for perimeter passes (by $19.6 \%, Z=-3.64$, $\mathrm{p}=0.001, \mathrm{~g}=0.86)$, which had the greatest share among all the passes in both groups $(59.5 \%$ and $73.7 \%$, respectively). A further analysis of the results in the context of the distance of the executed passes allows us to observe that, the highest share by far among all teams belonged to short passes, that is, to passes performed over the distance of a single pass (89-93\%). The rest of the classifications concerning the structure of the passes did not reveal any significant differences.

The analysis of the structure of the players' movements with the ball (Table 3 ) in terms of the diversification of the number of dribbles in individual sequences among the best teams 
292

298

299

304

305

showed a significantly lower number of single-dribble sequences (by $18.4 \%, \mathrm{t}=-3.27, \mathrm{p}<0.01$, $\mathrm{g}=0.65$ ) and four-dribble sequences (by $13.9 \%, \mathrm{t}=-2.41, \mathrm{p}<0.05, \mathrm{~g}=0.48$ ). In the study, a significant dominance of sequences with five or more dribbles was observed (around 7274\%) from among all the dribbles performed during the matches.

The basketball players representing the eight best teams at EuroBasket 2015 more often changed the direction of their dribbling by bouncing the ball under the leg (by $24.9 \%, t=2.09$, $\mathrm{p}<0.05, \mathrm{~g}=0.47$ ) in comparison to the players from the eight weakest teams. In both groups, the players with the ball most frequently changed the direction of their dribbling by using a cross-over dribble, with a percentage share of around $72-78 \%$.

The structure of offensive actions ending in a turnover executed by the players from both groups is presented in Table 4. It was observed that the total numbers of turnovers and bad passes were lower in the higher-ranking teams (by $12.4 \%, \mathrm{t}=-2.43, \mathrm{p}<0.05, \mathrm{~g}=0.51$; and by $19.0 \%, \mathrm{t}=-2.41, \mathrm{p}<0.05, \mathrm{~g}=0.52$, respectively). Bad passes constituted the highest share of all the turnovers (at about $40-44 \%$ ).

Table 5 presents the results of the regression analysis and model values for each manner of passing in relation to assists performed by the best $(\mathrm{F}=62.07 ; \mathrm{p}=0.001)$ and the weakest teams $(\mathrm{F}=55.85 ; \mathrm{p}=0.001)$ at EuroBasket 2015.The remaining independent variables that formed an optimal vector have been excluded from the regression model due to being statistically insignificant. 
311 The multiple forward stepwise regression analysis for the assists (A) dependent variable

312 established the function of a regression in the following form, based on the particular values

313 that were significant in the model of the independent variables:

$314 \mathrm{~A}=8.8601+0.0693 *$ One-handed with the right hand $+0.1101 *$ Two-handed overhead (eight

315 highest-ranking teams)

316

317

$\mathrm{A}=1.2097+0.1356 *$ Two-handed overhead $+0.1667 *$ Long $+0.0445 *$ Two-handed chest

318 (eliminated teams).

319

320

At the same time, the analysis showed that the most important predictor for the assists performed by the players from the eight best teams at EuroBasket 2015 were one-handed passes made with the right hand. On the other hand, the most important predictor for the assists performed by the players from the weakest teams were two-handed overhead passes.

\section{DISCUSSION}

The key aim, which at the same time constituted the main research objective presented in the Introduction section of this paper, was to determine the full structure of the passes performed during EuroBasket 2015. To a large extent, the applied division criteria of the technique of executing passes have not appeared in the studies conducted by other authors, but these are nonetheless extremely significant from a practical viewpoint. Subsequently, the results of the research concerning dribbling (including dribbling sequences, handwork and the changes of dribbling directions) have been presented and the causes of the turnovers suffered by the players analyzed. 
It can be concluded that the numbers of one-handed basic passes and passes made with the right hand were significantly higher in the teams that advanced into the top eight at EuroBasket 2015 than in the rest of the teams, and this stems from the fact that the onehanded basic pass is currently the primary pass used by the most well-trained players, especially those under high pressure from the defense (Krause et al., 2008). The player with the ball and his partner will attempt to create a passing lane, predominantly by using a onehanded pass. This allows the player with the ball to pass the ball over to the partner effectively, while evading the defensive player located between the two (Wissel, 2004). Because the vast majority of players were right-handed, both groups are dominated by righthanded passes.

Even though two-handed passes constituted the highest share in both of the compared groups, the share of these passes among the best teams was lower by $12.7 \%$ than the share of onehanded passes. The best players attempted to reduce the number of two-handed passes (especially chest passes) in favor of one-handed passes, which was indicated by the distribution of the passes according to the technical manner of passing. One-handed basic passes dominated among the best teams, and two-handed chest passes dominated among the weakest teams. Due to an increased pace of the game and improved defense, the players often performed a one-handed basic pass without catching the ball, immediately off the dribble, which considerably shortened the time between a player's decision to make a pass and the player's partner receiving the ball (Courel-Ibáñez et al., 2016, Maimón, Courel-Ibáñez \& Ruíz, 2020). When the player with the ball is under pressure and the others without the ball are also aggressively defended two aspects are extremely relevant - timing and passing line. It terms of that one-handed basic pass must be applied in order to deliver the ball to the open player at appropriate time. A precise and quick pass in correct timing is needed in order to 
361

362

363

364

365

366

367

368

369

370

371

372

transfer the ball effectively (Wissel, 2004). Different results were obtained in a study

conducted by Theoharopoulos et al. (Theoharopoulos et al., 2010), who indicated that twohanded chest and overhead passes play the dominant role (38.9\% and $24.9 \%$, respectively).

However, their study was conducted on matches of a significantly lower level.

Lobs, including alley-oop passes, were executed more frequently by the best teams, but overall, flat passes dominated. A lob is difficult to execute and requires a high synchronicity of actions between the player passing the ball and the partner (Courel-Ibáñez et al., 2016).

This is why this type of pass is used to a greater extent by advanced teams, who use more refined tactics than less experienced teams. Such tactics usually involves plays such as the pick and roll, backdoor cut, back picks, inside-outside, etc. (Courel, Suárez, Ortega, Piñar, \& Cárdenas, 2013; Gómez et al., 2015). That is why lobs are used to a large extent in such types of actions involving two or three players.

The fact that the best teams performed more running passes and jump passes than passes off the dribble indicates that the game enforced a higher pace throughout the tournament and a tendency to avoid dribbling if possible, which increased the speed of the ball and forced the players who did not have the ball to be highly active (Zhang, Lorenzo, Woods, Leicht \& Gómez, 2019). A fairly interesting finding in the study was that overall, passes while stationary were the dominant ones. This result is fairly surprising, considering the earlier findings. We may, however, find a confirmation of this result in a study by Andrić (Andrić, 2011), who concluded that in the European Championship in Poland in 2009, the players ended dribbling with a stop and a pass while stationary. 
In the case of the direction of the passes executed by the players of the best teams, a higher number of inside passes (by more than 62\%) were observed during the study. On the other hand, lower numbers were noted in relation to perimeter passes, which constituted the highest share of all passes in both groups. A further analysis of the research results in the context of the distance of the performed passes allowed us to observe that short passes had the highest share of all passes in all teams. These results indicate the dominance of the half-court offence that predominantly involved short passes. This concerns almost all the actions involving screens and offensive solutions, such as a drive and kick play followed by an extra pass. A higher number of inside passes among the best teams indicates that they used the inside play more often, while trying to transfer the ball to the center player close to the restricted area. Therefore, the conclusion of the study by Courel-Ibáñez et al. (Courel-Ibáñez et al., 2016) stating that increasing the number of actions focused on the inside game increases the effectiveness of offensive actions has been confirmed.

The analysis of the structure of the players' movements with the ball on the court showed a definite dominance of the sequence with five dribbles or more, taking into consideration all the data concerning this criterion. Dribbling is used in many situations: for transferring the ball from the backcourt to the frontcourt, for evading a defending player, for creating a passing lane and for avoiding a 'trap'. Usually, the players aim to reduce the number of dribbles in order to increase the speed and effectiveness of the game, which is why our result indicating the dominance of the sequences with five dribbles or more was surprising.

The basketball players representing the eight best teams at EuroBasket 2015 changed the direction of their dribbling under the leg more often in comparison to the players from the eight weakest teams. The players in both groups most frequently changed the direction of 
their dribbling by using a cross-over dribble, with the share of this technique amounting to

411 about $72-78 \%$ of the changes. This is an important point for basketball practice, as changes

412 behind the back and through a reverse dribble are executed much less frequently than the

413 cross-over dribble and by bouncing the ball under the leg. The latter is used especially in a

414 situation where the change cannot be made through a cross-over dribble, due to the defender

415 standing at a close distance. The dominant position of the change through a cross-over dribble

416 stems from the fact that this technique is the easiest, the quickest and allows for a correct

417 observation of the frontcourt. Similar results were obtained by Andrić (Andrić, 2011), who

418 investigated the frequency and effectiveness of various types of dribbling during the Senior

419 European Championship in 2009 in Poland. The abovementioned study indicates that the

420 dominant variant in changing the direction of the dribbling was the change performed in

421 through a cross-over dribble (61\% of changes of the dribbling direction). The same study

422 indicated that the change under the leg was the second most frequently used technique for

423 changing the direction of the dribbling (23\%).

424

The analysis of the structure of the offensive actions that ended in a turnover revealed a lower

number of total turnovers and bad passes among the higher-ranking teams (by $12.4 \%$ and $19.0 \%$, respectively). However, the highest share of turnovers was caused by bad passes (around 40-44\%). A pass, as opposed to dribbling which is an individual action, is a twoplayer action requiring cooperation between the player making the pass and the receiving partner (Sampaio et al., 2015). The likelihood of an error is considerably higher in the case of the latter, which in turn makes a bad pass the dominant cause of turnovers. The lower number of turnovers among the best teams at the European Championship indicates the better training of the individual players in these teams, resulting in more optimal use of the basic forms of 
particular situations during a game. The obtained results were consistent with those obtained by Fylaktakidou et al. (Fylaktakidou, Tsamourtzis, \& Zaggelidis, 2011). These authors analyzed 43 games in the women's A1 national league and concluded that at this level, the main causes were bad passes $(40.2 \%)$, travelling (23.6\%) and handling the ball $(23.9 \%)$.

The analysis of regression for each passing technique in relation to assists executed by the best and the worst teams at EuroBasket 2015 indicated that, for the players from the top-eight teams at EuroBasket 2015, the most important predictor for the assist variable was onehanded passes performed with the right hand. Conversely, the most important predictor for the assists performed by the players from the weakest teams was two-handed overhead passes. An assist is a pass that precedes the successful finish of an offensive action (Miller, 1994). Determining a prognostic factor for this variable has a significant practical dimension and indicates the necessity for the continuous improvement of passing skills, especially the skill required to execute one-handed passes. The fact that the study results indicated that the players used their stronger hand also suggests that the teams organized their offensive tactics such that the individual players would perform the majority of the actions with their stronger hand and to the stronger side.

\section{Limitations}

The potential scientific criticisms regarding the results of this study are related to the fact that, in order to provide a full explanation of the observed trends, other variables justifying the researched phenomenon should also be taken into consideration. The present study does not discuss the effects of a defending player and the pressures exerted on a player with the ball who is performing a pass. We have been evaluating the same teams in several games, however they competed with different opponents. The quality of teams they played 
against changed and the achieved data might be affected by this factor. Besides the results can

461 be dependent on the level of players taking part in the competition. Usually better skilled

462 athletes are able to perform much better compared to those less advanced. It also has impact

463 on the value of analyzed structural game variables for example passing outcome. The

464 collected data were coming from European Championship. All games during this kind of

465 FIBA competition are organized under standardized conditions. Therefore, it is hard to say

466 that the distance of passing may be influenced by game location. It seems to be interesting

467 goal for next research to discover the passing quality in terms of that factor. It would also be

468 worthwhile to obtain information about which types of passes were performed depending on

469 the offensive systems (fast break offences and half-court offences). Another issue worth

470 taking into account is an analysis of the passes according to the zone where the pass was

471 made and received. Lastly, an analysis of the causes of the turnovers (the greatest share of

472 which belonged to bad passes) would lead to the question regarding the technical manner of

473 passing in the case of bad passes. However, this would require new classifications with

474 division criteria to be designed, which may be a starting point for another study. Furthermore,

475 more precise data is required in the context of the decisions made by the players in the

476 moment of a pass, which would contribute to a more detailed analysis. This also refers to

477 information about the tactical solutions used in the offensive play among the observed teams,

478 since a specific plan of play may determine the execution of an action. However, this would

479 require cooperating with the coaches, who would have to provide us with the detailed

480 offensive 'playbook' of their teams.

481

482 CONCLUSIONS

483 
484 To sum up the results of the study in the context of the practical recommendations, it should

485 be emphasized that coaches must currently incorporate two elements of passing technique into 486 their training regime: primarily, one-handed passes (in particular, one-handed basic passes);

487 and secondly, two-handed passes (overhead and chest passes). We should look for solutions

488 intended to increase the number of inside passes, creating inside plays and cooperation

489 between short and tall players. In particular, the training should pay special attention to short

490 passes. As far as the manner of changing the direction of the dribbling is concerned, a focus

491 should be placed on changing the direction of the dribbling through a cross-over dribble and

492 by bouncing the ball under the leg. Coaches, first and foremost, should devote more time to

493 developing perfect passes, at the cost of dribbling, which can be concluded from the fact that

494 the main cause of turnovers is connected with passes and not with dribbling.

495

496

ACKNOWLEDGEMENT

497

498

The authors would like to thank the Polish Basketball Federation for its help in obtaining and 499 sharing the source materials.

500

501 REFERENCES

502

503

504

505

506

Andrić, M. (2011). Analysis of frequency and efficiency of using dribble in the European Basketball Championship in Poland in 2009. Phys Cult, 65(1), 52-59.

Angel, G. M., Tsamourtzis, E., \& Lorenzo, A. (2006). Defensive systems in basketball ball possessions. Int J Perform Anal Sport, 6(1), 98-107. 
Arias-Estero, J. L. (2013). Opportunities for and success in dribbling, passing, receiving, and shooting in youth basketball. International Journal of Sports Science and Coaching, 8(4), 703-711. doi: 10.1260/1747-9541.8.4.703

Arias-Estero, J. L., Argudo, F. M., \& Alonso, J. I. (2018). One-on-one situation decisionmaking according to equipment in youth basketball. International Journal of Sports Science and Coaching, 13(1), 72-77. doi: 10.1177/1747954117746494

Arias, J. L., Argudo, F. M., \& Alonso, J. I. (2012). Effect of ball mass on dribble, pass, and pass reception in 9-11-year-old boys' basketball. Research Quarterly for Exercise and Sport, 83(3), 407-412. doi: 10.1080/02701367.2012.10599875

Bredt, S. G. T., Morales, J. C. P., Andrade, A. G. P., Torres, J. O., Peixoto, G. H., Greco, P. J., Chagas, M. H. (2018). Space Creation Dynamics in Basketball Small-Sided Games. Perceptual and Motor Skills, 125(1), 162-176. doi: 10.1177/0031512517725445

Cárdenas, D., Ortega, E., Llorca, J., Courel-Ibáñez, J., Sánchez-Delgado, G., \& Piñar, M. I. (2015). Motor characteristics of fast break in high level basketball. Kinesiology, 47(2), 208-214.

Chang, S. C. (2018). Capability and opportunity in hot shooting performance: Evidence from top-scoring NBA leaders. PLoS ONE, 13(2). doi: 10.1371/journal.pone.0179154

Conte, D., Favero, T. G., Niederhausen, M., Capranica, L., \& Tessitore, A. (2016). Effect of different number of players and training regimes on physiological and technical demands of ball-drills in basketball. Journal of Sports Sciences, 34(8), 780-786. doi: $10.1080 / 02640414.2015 .1069384$

Conte, D., Favero, T. G., Niederhausen, M., Capranica, L., \& Tessitore, A. (2017). Determinants of the effectiveness of fast break actions in elite and sub-elite Italian men's basketball games. Biology of Sport, 34(2), 177-183. doi: 10.5114/biolsport.2017.65337 
531 Courel, J., Suárez, E., Ortega, E., Piñar, M., \& Cárdenas, D. (2013). Is the inside pass a

532

533

534

535

536

537

538

539

540

541

542

543

544

545

546

547

548

549

550

551

552

553 performance indicator? Observational analysis of elite basketball teams. Revista de Psicología Del Deporte, 22(1), 191-194.

Courel-Ibáñez, J., McRobert, A. P., Toro, E. O., \& Vélez, D. C. (2016). Inside pass predicts ball possession effectiveness in NBA basketball. International Journal of Performance Analysis in Sport, 16(2), 711-725. doi: 10.1080/24748668.2016.11868918

Cronbach, L. J. (1951). Coefficient alpha and the internal structure of tests. Psychometrika, 16(3), 297-334.doi: 10.1007/bf023105

Csataljay, G., James, N., Hughes, M., \& Dancs, H. (2013). Effects of defensive pressure on basketball shooting performance. International Journal of Performance Analysis in Sport, 13(3), 594-601. doi: 10.1080/24748668.2013.11868673

Csataljay, G., O’Donoghue, P., Hughes, M., \& Dancs, H. (2009). Performance indicators that distinguish winning and losing teams in basketball. Int J Perform Anal Sport, 9(1), 6066.

Ellis, P. (2010). The essential guide to effect sizes: statistical power, meta-analysis, and the interpretation of research results. Cambridge University Press.

Erčulj, F., \& Štrumbelj, E. (2015). Basketball shot types and shot success in different levels of competitive basketball. PLoS ONE, 10(6). doi: 10.1371/journal.pone.0128885

Fylaktakidou, A., Tsamourtzis, E., \& Zaggelidis, G. (2011). The turnovers analysis to the Women's National League basketball games. Sport Sci Rev, 20(3-4), 69-83.

Gómez, M. Á., Battaglia, O., Lorenzo, A., Lorenzo, J., Jiménez, S., \& Sampaio, J. (2015). Effectiveness during ball screens in elite basketball games. Journal of Sports Sciences, 33(17), 1844-1852. doi: 10.1080/02640414.2015.1014829 
554 Gómez, M. Á., Lorenzo, A., Sampaio, J., Ibáñez, S. J., \& Ortega, E. (2008). Game-related 555 statistics that discriminated winning and losing teams from the Spanish Men's 556 Professional Basketball Teams. Collegium Antropologicum, 32(2), 451-456.

557 Gómez, M. A., Tsamourtzis, E., \& Alberto, L. (2006). Defensive systems in basketball ball $558 \quad$ possessions. Int J Perform Anal Sport, 6(1), 98-107.

559 Gryko, K., Mikołajec, K., Maszczyk, A., Cao, R., \& Adamczyk, J. G. (2018). Structural 560 analysis of shooting performance in elite basketball players during FIBA EuroBasket

Gryko, K., Słupczyński, B., \& Kopiczko, A. (2016). Impact of regulation change on half-court 564 2015. International Journal of Performance Analysis in Sport, 18(2), 380-392. doi: $10.1080 / 24748668.2018 .1479923$ offence in the Polish basketball league. Pol J Sport Tour, 23(2), 70-75.

Ibáñez, S., Sampaio, J., Feu, S., Lorenzo, A., Gomez, M., \& Ortega, E. (2008). Basketball game-related statistics that discriminate between teams' season-long success. European Journal of Sport Science, 8(6), 369-372. doi: 10.1080/17461390802261470

Ibáñez, S. J., Sampaio, J., Sáenz-López, P., Giménez, J., \& Janeira, M. A. (2003). Game statistics discriminating the final outcome of junior world basketball championship matches (Portugal 1999). Journal of Human Movement Studies, 45(1), 1-19.

Koo, T.K., \& Li, M.Y. (2016). A Guideline of Selecting and Reporting Intraclass Correlation Coefficients for Reliability Research. Journal of chiropractic medicine, 15(2), 155-163. doi:10.1016/j.jcm.2016.02.012

Krause, J., Meyer, D., \& Meyer, J. (2008). Basketball skills and drills (3rd ed.). Champaign, IL: Human Kinetics.

Maimón, A., Courel-Ibáñez, J. \& Ruíz, F. (2020). The Basketball Pass: A Systematic Review. Journal of Human Kinetics, 71(1), 275-284. doi:10.2478/hukin-2019-0088 
578 McCormick, B., Hannon, J., Newton, M., Shultz, B., Miller, N., \& Young, W. (2012).

579 Comparison of physical activity in small-sided basketball games versus full-sided games. International Journal of Sports Science and Coaching, 7(4), 689-697. doi:

Miller, R. (1994). The passing game. In J. Krause (Ed.), Coaching basketball (pp. 117-118). Indianapolis, IN: Masters Press.

O’Donoghue, P. (2009). Research methods for sports performance analysis. London: Routledge.

Oudejans, R., Karamat, R., \& Stolk, M. (2012). Effects of actions preceding the jump shot on gaze behavior and shooting performance in elite female basketball players. International Journal of Sports Science and Coaching, 7(2), 255-267. doi: $10.1260 / 1747-9541.7 .2 .255$

Sampaio, J., Leser, R., Baca, A., Calleja-Gonzalez, J., Coutinho, D., Gonçalves, B., \& Leite, N. (2016). Defensive pressure affects basketball technical actions but not the timemotion variables. Journal of Sport and Health Science, 5(3), 375-380. doi: 10.1016/j.jshs.2015.01.011

Sampaio, J., McGarry, T., Calleja-González, J., Jiménez Sáiz, S., Schelling i del Alcázar, X., \& Balciunas, M. (2015). Exploring Game Performance in the National Basketball Association Using Player Tracking Data. PloS ONE, 10(7), e0132894. https://doi.org/10.1371/journal.pone.0132894

Taber, K.S. (2018). The Use of Cronbach's Alpha When Developing and Reporting Research Instruments in Science Education. Res Sci Educ 48, 1273-1296. https://doi.org/10.1007/s11165-016-9602-2 
601 Theoharopoulos, A., Lapardis, K., Galazoulas, C., \& Tsitskaris, G. (2010). A comparative study 602 relating pass between male and female basketball players. J Phys Ed Sport, 26(1), 44603 50.

604 Trninić, S., Karalejić, M., Jakovljević, S., \& Jelaska, I. (2010). Structural analysis of knowledge 605 based on specific attributes of the game of basketball. Phys Cult, 64(2), 22-41.

606 Tsamourtzis, E., Karypidis, A., \& Athanasiou, N. (2005). Analysis of fast breaks in basketball. 607 Int J Perform Anal Sport, 5(2), 17-22.

608 Wissel, H. (2004). Basketball steps to success (2nd ed.). Champaign, IL: Human Kinetics.

609 Wootten, M., \& Gilbert, D. (2013). Coaching basketball successfully (3rd ed.). Champaign, IL: $610 \quad$ Human Kinetics.

611 Zhang, S., Lorenzo, A., Woods, C. T., Leicht, A. S., \& Gómez, M.-A. (2019). Evolution of 612 game-play characteristics within-season for the National Basketball Association. 613 International Journal of Sports Science \& Coaching, 14(3), 355-362. 614 https://doi.org/10.1177/174795411984717

615

616

617

618

619

620

621

622

623

624

625 
626 TABLE 1 Cronbach's $\alpha$ statistic and percentage of inter-observer agreement for each dataset

\begin{tabular}{|c|c|c|c|c|}
\hline \multirow{2}{*}{ Variables } & \multicolumn{2}{|c|}{ Eight highest-ranking teams } & \multicolumn{2}{|c|}{ Eliminated teams } \\
\hline & $\alpha$ & $\%$ Agreement & $\alpha$ & $\%$ Agreement \\
\hline With the creation of a passing lane & 0,9252 & $93 \%$ & 0,8248 & $82 \%$ \\
\hline Without creating a passing lane & 0,8457 & $85 \%$ & 0,8492 & $85 \%$ \\
\hline One-handed pass with the right hand & 0,8407 & $84 \%$ & 0,9649 & $96 \%$ \\
\hline One-handed pass with the left hand & 0,9785 & $98 \%$ & 0,8382 & $84 \%$ \\
\hline Two-handed pass & 0,8542 & $85 \%$ & 0,8955 & $90 \%$ \\
\hline Two-handed chest pass & 0,8707 & $87 \%$ & 0,8552 & $86 \%$ \\
\hline One-handed overhead pass & 0,9560 & $96 \%$ & 0,9036 & $90 \%$ \\
\hline One-handed basic pass & 0,8617 & $86 \%$ & 0,9046 & $90 \%$ \\
\hline Baseball pass & 0,8282 & $83 \%$ & 0,8241 & $82 \%$ \\
\hline Hook pass & 0,8141 & $81 \%$ & 0,9055 & $91 \%$ \\
\hline Behind-the-back pass & 0,8559 & $86 \%$ & 0,8767 & $88 \%$ \\
\hline Situation-related pass & 0,9759 & $98 \%$ & 0,9633 & $96 \%$ \\
\hline Flat & 0,9770 & $98 \%$ & 0,8366 & $84 \%$ \\
\hline Lob & 0,8749 & $87 \%$ & 0,8557 & $86 \%$ \\
\hline Bounce pass & 0,8463 & $85 \%$ & 0,8725 & $87 \%$ \\
\hline Hand-off pass & 0,9439 & $94 \%$ & 0,8889 & $89 \%$ \\
\hline While stationary & 0,9173 & $92 \%$ & 0,8435 & $84 \%$ \\
\hline While running & 0,8931 & $89 \%$ & 0,8894 & $89 \%$ \\
\hline Off the dribble & 0,8861 & $89 \%$ & 0,9380 & $94 \%$ \\
\hline Jump pass & 0,8895 & $89 \%$ & 0,9842 & $98 \%$ \\
\hline Perimeter & 0,8632 & $86 \%$ & 0,9162 & $92 \%$ \\
\hline Inside & 0,9544 & $95 \%$ & 0,9400 & $94 \%$ \\
\hline Outside & 0,8464 & $85 \%$ & 0,8784 & $88 \%$ \\
\hline Short pass & 0,8390 & $84 \%$ & 0,9795 & $98 \%$ \\
\hline Long & 0,8868 & $89 \%$ & 0,8488 & $85 \%$ \\
\hline Skip pass & 0,8201 & $82 \%$ & 0,9161 & $92 \%$ \\
\hline One-handed & 0,9723 & $97 \%$ & 0,9264 & $93 \%$ \\
\hline Two-handed & 0,9877 & $99 \%$ & 0,8378 & $84 \%$ \\
\hline 1 dribble & 0,9198 & $92 \%$ & 0,9713 & $97 \%$ \\
\hline 2 dribbles & 0,9534 & $95 \%$ & 0,9078 & $91 \%$ \\
\hline 3 dribbles & 0,8295 & $83 \%$ & 0,8330 & $83 \%$ \\
\hline 4 dribbles & 0,8713 & $87 \%$ & 0,8699 & $87 \%$ \\
\hline 5 or more dribbles & 0,9149 & $91 \%$ & 0,9742 & $97 \%$ \\
\hline Right hand & 0,9212 & $92 \%$ & 0,8617 & $86 \%$ \\
\hline Left hand & 0,9492 & $95 \%$ & 0,8372 & $84 \%$ \\
\hline With the change of hands & 0,8862 & $89 \%$ & 0,9647 & $96 \%$ \\
\hline Cross-over dribble & 0,9810 & $98 \%$ & 0,9242 & $92 \%$ \\
\hline Under the leg & 0,8565 & $86 \%$ & 0,8315 & $83 \%$ \\
\hline Behind the back & 0,8248 & $82 \%$ & 0,9171 & $92 \%$ \\
\hline Reverse dribble & 0,8343 & $83 \%$ & 0,9535 & $95 \%$ \\
\hline Total turnovers & 0,9368 & $94 \%$ & 0,9261 & $93 \%$ \\
\hline Loss of the ball & 0,9463 & $95 \%$ & 0,9334 & $93 \%$ \\
\hline Travelling & 0,9886 & $99 \%$ & 0,9556 & $96 \%$ \\
\hline Bad pass & 0,9764 & $98 \%$ & 0,8326 & $83 \%$ \\
\hline Offensive foul & 0,9892 & $99 \%$ & 0,9021 & $90 \%$ \\
\hline Received block & 0,8915 & $89 \%$ & 0,9873 & $99 \%$ \\
\hline Time violation by the player & 0,9242 & $92 \%$ & 0,8697 & $87 \%$ \\
\hline Time violation by the team & 0,9904 & $99 \%$ & 0,9710 & $97 \%$ \\
\hline
\end{tabular}


TABLE 2 Diversification of the structure of the passes and catches in the studied teams during FIBA EuroBasket 2015

\begin{tabular}{|c|c|c|c|c|c|c|c|c|c|c|}
\hline & \multirow{2}{*}{\multicolumn{2}{|c|}{ Type of pass }} & \multicolumn{3}{|c|}{ Eight highest-ranking teams $(n=70)$} & \multicolumn{3}{|c|}{ Eliminated teams $(n=40)$} & \multirow{2}{*}{$\begin{array}{c}\text { Test value } \\
\text { (p-value) }\end{array}$} & \multirow{2}{*}{$\begin{array}{l}\text { Effect size } \\
\text { Hedges'g }\end{array}$} \\
\hline & & & $\overline{\mathbf{X}} \pm \mathbf{S D}$ & $\begin{array}{l}\% \text { of the } \\
\text { total }\end{array}$ & $\begin{array}{c}95 \% \text { confidence } \\
\text { interval }\end{array}$ & $\overline{\mathbf{X}} \pm \mathbf{S D}$ & $\begin{array}{c}\% \text { of } \\
\text { the } \\
\text { total }\end{array}$ & $\begin{array}{l}95 \% \text { confidence } \\
\text { interval }\end{array}$ & & \\
\hline \multicolumn{3}{|c|}{ Total passes } & $252.9 \pm 30.7$ & 100 & $245.4-260.4$ & $253.8 \pm 30.9$ & 100 & $243.7-263.8$ & $\begin{array}{c}-0.1432 \\
(0.8864)\end{array}$ & 0.0292 \\
\hline \multirow{2}{*}{$\begin{array}{l}\text { According to } \\
\text { the passing lane }\end{array}$} & \multicolumn{2}{|c|}{ With the creation of a passing lane } & $55.6 \pm 37.3$ & 22.0 & $46.5-64.7$ & $68.2 \pm 22.7$ & 26.9 & $60.8-75.6$ & $\begin{array}{l}-1.9107 \\
(0.0588)\end{array}$ & 0.3843 \\
\hline & \multicolumn{2}{|c|}{ Without creating a passing lane } & $197.3 \pm 45.7$ & 78.0 & $186.2-208.5$ & $185.6 \pm 33.6$ & 73.1 & $174.2-196.0$ & $\begin{array}{c}1.4566 \\
(0.1482)\end{array}$ & 0.2803 \\
\hline \multirow{10}{*}{$\begin{array}{l}\text { According to } \\
\text { the handwork }\end{array}$} & \multirow{3}{*}{$\begin{array}{l}\text { According } \\
\text { to the } \\
\text { passing } \\
\text { hand }\end{array}$} & $\begin{array}{l}\text { One-handed pass } \\
\text { with the right hand }\end{array}$ & $94.0 \pm 32.8$ & 37.2 & $80.6-96.6$ & $67.3 \pm 24.2 * * *$ & 26.5 & $58.9-74.6$ & $\begin{array}{c}4.2682 \\
(0.0001)\end{array}$ & 0.8905 \\
\hline & & $\begin{array}{l}\text { One-handed pass } \\
\text { with the left hand }\end{array}$ & $24.8 \pm 13.8$ & 9.8 & $21.5-28.2$ & $19.9 \pm 12.1$ & 7.8 & $15.9-23.9$ & $\begin{array}{c}1.8433 \\
(0.0681)\end{array}$ & 0.3709 \\
\hline & & Two-handed pass & $134.1 \pm 47.8$ & 53.0 & $122.4-145.7$ & $166.6 \pm 40.4 * * *$ & 65.7 & $153.5-179.7$ & $\begin{array}{l}-3.6393 \\
(0.0003)\end{array}$ & 0.7180 \\
\hline & \multicolumn{2}{|c|}{ Two-handed chest pass } & $88.3 \pm 30.8$ & 34.9 & $86.7-101.7$ & $122.4 \pm 28.6^{* * *}$ & 48.2 & $113.1-131.7$ & $\begin{array}{l}-4.5728 \\
(0.0001)\end{array}$ & 1.1358 \\
\hline & \multicolumn{2}{|c|}{ One-handed overhead pass } & $45.8 \pm 13.2$ & 18.1 & $42.5-49.0$ & $44.2 \pm 14.6$ & 17.4 & $39.5-48.9$ & $\begin{array}{c}0.5677 \\
(0.5714)\end{array}$ & 0.1166 \\
\hline & \multicolumn{2}{|c|}{ One-handed basic pass } & $107.1 \pm 44.2$ & 42.3 & $93.2-114.8$ & $77.3 \pm 36.5 * * *$ & 30.5 & $65.5-89.2$ & $\begin{array}{c}3.2953 \\
(0.0010)\end{array}$ & 0.7166 \\
\hline & \multicolumn{2}{|c|}{ Baseball pass } & $2.7 \pm 2.4$ & 1.1 & $1.9-3.3$ & $1.5 \pm 1.8$ & 0.6 & $0.6-1.8$ & $\begin{array}{c}1.0482 \\
(0.2969)\end{array}$ & 0.5449 \\
\hline & \multicolumn{2}{|l|}{ Hook pass } & $2.8 \pm 2.5$ & 1.1 & $1.7-2.9$ & $1.9 \pm 1.7$ & 0.7 & $1.4-2.5$ & $\begin{array}{c}0.8968 \\
(0.3719)\end{array}$ & 0.4010 \\
\hline & \multicolumn{2}{|c|}{ Behind-the-back pass } & $0.9 \pm 0.7$ & 0.4 & $0.5-1.1$ & $0.3 \pm 0.9$ & 0.2 & $0.0-0.6$ & $\begin{array}{c}1.1384 \\
(0.2576)\end{array}$ & 0.7710 \\
\hline & \multicolumn{2}{|c|}{ Situation-related pass } & $5.3 \pm 7.4$ & 2.1 & $3.1-6.6$ & $6.2 \pm 9.3$ & 2.4 & $2.9-8.9$ & $\begin{array}{c}-0.7299 \\
(0.4671)\end{array}$ & 0.1106 \\
\hline
\end{tabular}




\begin{tabular}{|c|c|c|c|c|c|c|c|c|c|}
\hline \multirow{4}{*}{$\begin{array}{l}\text { According to } \\
\text { the flight path } \\
\text { of the ball }\end{array}$} & Flat & $183.4 \pm 27.2$ & 72.5 & $176.8-190.1$ & $187.1 \pm 27.7$ & 73.7 & $178.1-196.1$ & $\begin{array}{l}-0.6673 \\
(0.5060)\end{array}$ & 0.1351 \\
\hline & Lob & $19.1 \pm 9.5$ & 7.5 & $17.2-21.9$ & $13.1 \pm 13.4 * * *$ & 5.2 & $9.0-17.7$ & $\begin{array}{c}4.1372 \\
(0.0001)\end{array}$ & 0.5421 \\
\hline & Bounce pass & $33.3 \pm 10.5$ & 13.2 & $30.7-35.9$ & $35.5 \pm 9.9$ & 14.0 & $32.2-38.7$ & $\begin{array}{l}-1.0480 \\
(0.2970)\end{array}$ & 0.2139 \\
\hline & Hand-off pass & $17.1 \pm 7.4$ & 6.8 & $15.3-18.9$ & $18.1 \pm 4.6$ & 7.1 & $16.8-19.8$ & $\begin{array}{l}-0.8898 \\
(0.3756)\end{array}$ & 0.1532 \\
\hline \multirow{4}{*}{$\begin{array}{l}\text { According to } \\
\text { the movement }\end{array}$} & While stationary & $165.2 \pm 29.9$ & 65.4 & $158.9-173.6$ & $160.9 \pm 30.2$ & 63.4 & $151.2-170.7$ & $\begin{array}{c}0.8157 \\
(0.4147)\end{array}$ & 0.1433 \\
\hline & While running & $26.1 \pm 17.2$ & 10.3 & $21.9-30.3$ & $16.5 \pm 20.6 * * *$ & 6.5 & $9.8-23.2$ & $\begin{array}{c}3.8292 \\
(0.0001)\end{array}$ & 0.5190 \\
\hline & Off the dribble & $50.3 \pm 27.7$ & 19.9 & $44.1-57.6$ & $68.1 \pm 27.1^{* *}$ & 26.8 & $59.3-76.9$ & $\begin{array}{l}-2.6926 \\
(0.0071)\end{array}$ & 0.6476 \\
\hline & Jump pass & $11.3 \pm 5.4$ & 4.4 & $10.0-12.6$ & $8.3 \pm 5.4 * *$ & 3.3 & $7.1-10.6$ & $\begin{array}{c}2.9481 \\
(0.0032)\end{array}$ & 0.5556 \\
\hline \multirow{3}{*}{$\begin{array}{l}\text { According to } \\
\text { the direction }\end{array}$} & Perimeter & $150.5 \pm 49.1$ & 59.5 & $138.5-162.5$ & $187.1 \pm 28.0 * * *$ & 73.7 & $178.1-196.2$ & $\begin{array}{l}-3.6458 \\
(0.0003)\end{array}$ & 0.8571 \\
\hline & Inside & $57.7 \pm 22.5$ & 22.8 & $52.3-63.2$ & $35.6 \pm 15.6^{* * * *}$ & 14.0 & $30.4-40.5$ & $\begin{array}{c}5.3852 \\
(0.0001)\end{array}$ & 1.0897 \\
\hline & Outside & $44.7 \pm 8.5$ & 17.7 & $37.7-50.4$ & $31.1 \pm 8.9$ & 12.3 & $28.2-34.0$ & $\begin{array}{c}1.8671 \\
(0.0619)\end{array}$ & 1.5729 \\
\hline \multirow{3}{*}{$\begin{array}{l}\text { According to } \\
\text { the distance }\end{array}$} & $\begin{array}{l}\text { Short pass (over the distance of one } \\
\text { pass) }\end{array}$ & $227.4 \pm 38.4$ & 89.9 & $218.0-236.7$ & $233.7 \pm 34.1$ & 92.1 & $222.6-244.7$ & $\begin{array}{l}-0.8477 \\
(0.3985)\end{array}$ & 0.1707 \\
\hline & Long & $20.8 \pm 14.9$ & 8.2 & $17.1-24.4$ & $17.5 \pm 10.4$ & 6.9 & $14.5-21.3$ & $\begin{array}{c}1.0530 \\
(0.2948)\end{array}$ & 0.2453 \\
\hline & Skip pass & $4.7 \pm 5.9$ & 1.9 & $3.2-6.1$ & $2.6 \pm 3.5$ & 1.0 & $1.4-3.7$ & $\begin{array}{c}1.6935 \\
(0.0904)\end{array}$ & 0.4067 \\
\hline \multirow{2}{*}{ Catches } & One-handed & $34.4 \pm 3.1$ & 13.6 & $28.8-40.1$ & $35.9 \pm 4.2$ & 14.1 & $28.7-43.2$ & $\begin{array}{l}-0.3238 \\
(0.7467)\end{array}$ & 0.4240 \\
\hline & Two-handed & $218.5 \pm 10.3$ & 86.4 & $208.2-227.2$ & $217.9 \pm 9.8$ & 85.9 & $204.3-231.6$ & $\begin{array}{c}1.0221 \\
(0.3471)\end{array}$ & 0.0593 \\
\hline
\end{tabular}


Note: Statistically significant difference between the teams placed $1-8$ and the other teams: ${ }^{* *} \mathbf{p}<\mathbf{0 . 0 1}, * * * \mathbf{p}<\mathbf{0 . 0 0 1}$. 
TABLE 3 Diversification of the movement structure on the court with the ball during FIBA EuroBasket 2015

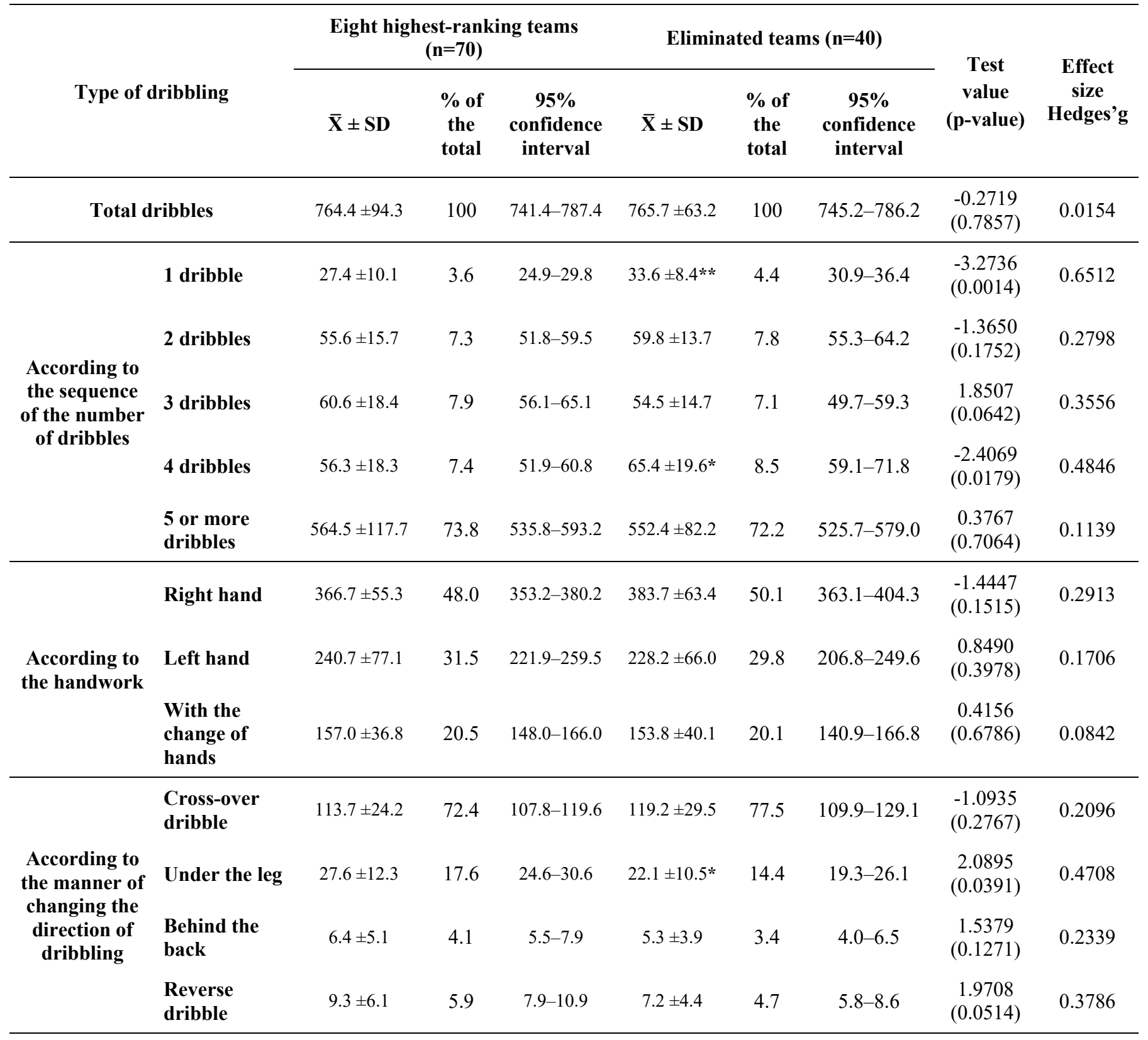

Note: Statistically significant difference between the teams placed $1-8$ and the other teams: $* \mathbf{p}<\mathbf{0 . 0 5}, * *$ $\mathbf{p}<\mathbf{0 . 0 1}$. 
TABLE 4 Diversification of the number of actions ending in a turnover performed by the studied teams during FIBA EuroBasket 2015

\begin{tabular}{|c|c|c|c|c|c|c|c|c|}
\hline \multirow[b]{2}{*}{ Type of turnover } & \multicolumn{3}{|c|}{$\begin{array}{l}\text { Eight highest-ranking teams } \\
\qquad(n=70)\end{array}$} & \multicolumn{3}{|c|}{ Eliminated teams $(n=40)$} & \multirow{2}{*}{$\begin{array}{c}\text { Test } \\
\text { value } \\
\text { (p-value) }\end{array}$} & \multirow{2}{*}{$\begin{array}{l}\text { Effect size } \\
\text { Hedges'g }\end{array}$} \\
\hline & $\overline{\mathbf{X}} \pm \mathbf{S D}$ & $\begin{array}{l}\% \text { of } \\
\text { the } \\
\text { total }\end{array}$ & $\begin{array}{c}95 \% \\
\text { confidence } \\
\text { interval }\end{array}$ & $\overline{\mathbf{X}} \pm \mathbf{S D}$ & $\begin{array}{l}\% \text { of } \\
\text { the } \\
\text { total }\end{array}$ & $\begin{array}{c}95 \% \\
\text { confidence } \\
\text { interval }\end{array}$ & & \\
\hline Total turnovers & $12.7 \pm 3.6$ & 100 & $11.8-13.6$ & $14.5 \pm 3.4^{*}$ & 100 & $13.4-15.5$ & $\begin{array}{l}-2.4271 \\
(0.0169)\end{array}$ & 0.5100 \\
\hline Loss of the ball & $3.3 \pm 1.7$ & 26.0 & $2.9-3.7$ & $3.8 \pm 1.8$ & 26.2 & $3.2-4.4$ & $\begin{array}{l}-1.4096 \\
(0.1616)\end{array}$ & 0.2879 \\
\hline Travelling & $0.8 \pm 1.1$ & 6.3 & $0.6-1.1$ & $0.8 \pm 0.8$ & 5.6 & $0.5-1.1$ & $\begin{array}{c}0.1999 \\
(0.8419)\end{array}$ & 0.0000 \\
\hline Bad pass & $5.1 \pm 2.3$ & 40.2 & $4.6-5.7$ & $6.3 \pm 2.3 *$ & 43.4 & $5.5-7.0$ & $\begin{array}{l}-2.4143 \\
(0.0175)\end{array}$ & 0.5217 \\
\hline Offensive foul & $1.2 \pm 1.0$ & 9.4 & $1.0-1.5$ & $1.5 \pm 1.4$ & 10.3 & $1.0-1.9$ & $\begin{array}{l}-0.5241 \\
(0.6002)\end{array}$ & 0.2585 \\
\hline Received block & $1.6 \pm 1.5$ & 12.6 & $1.2-2.0$ & $1.5 \pm 1.3$ & 10.3 & $1.1-1.9$ & $\begin{array}{c}0.3833 \\
(0.7045)\end{array}$ & 0.0699 \\
\hline $\begin{array}{l}\text { Time violation by } \\
\text { the player }\end{array}$ & $0.2 \pm 0.4$ & 1.6 & $0.1-0.2$ & $0.1 \pm 0.3$ & 0.7 & $0.1-0.2$ & $\begin{array}{c}0.7617 \\
(0.4479)\end{array}$ & 0.2724 \\
\hline $\begin{array}{l}\text { Time violation by } \\
\text { the team }\end{array}$ & $0.5 \pm 0.7$ & 3.9 & $0.3-0.6$ & $0.5 \pm 0.6$ & 3.5 & $0.3-0.7$ & $\begin{array}{l}-0.5636 \\
(0.5743)\end{array}$ & 0.0000 \\
\hline
\end{tabular}

Note: Statistically significant difference between the teams placed $1-8$ and the other teams: ${ }^{*} \mathbf{p}<\mathbf{0 . 0 5}$. 
TABLE 5 Summary of the multiple forward stepwise regression for assists executed by players from the best and the weakest teams during FIBA EuroBasket 2015

\begin{tabular}{|c|c|c|c|c|c|c|}
\hline \multirow{2}{*}{ Type of pass } & $\beta$ & B & $\mathbf{p}$ & $\begin{array}{c}\text { Adjusted } \\
\qquad \mathbf{R}^{\mathbf{2}}\end{array}$ & $\mathbf{F}$ & $\mathbf{p}$ \\
\hline & \multicolumn{6}{|c|}{ Eight highest-ranking teams $(n=70)$} \\
\hline Absolute term & & 8.8601 & 0.0133 & & & \\
\hline One-handed with the right hand & 0.4763 & 0.0693 & 0.0007 & 0.6411 & 28.74 & 0.0028 \\
\hline \multirow[t]{2}{*}{ Two-handed overhead } & 0.3047 & 0.1101 & 0.0262 & & & \\
\hline & \multicolumn{6}{|c|}{ Eliminated teams $(n=40)$} \\
\hline Absolute term & & 1.2097 & 0.7099 & & & \\
\hline Two-handed overhead & 0.4860 & 0.1356 & 0.0005 & 0.7508 & 21.34 & 0.0001 \\
\hline Long & 0.4270 & 0.1667 & 0.0020 & & & \\
\hline Two-handed chest & 0.3128 & 0.0445 & 0.0205 & & & \\
\hline
\end{tabular}

